\title{
Enhancement of pipecolic acid production by the expression of multiple lysine cyclodeaminase in the Escherichia coli whole-cell system
}

\author{
Yeong-Hoon Han ${ }^{1}$, Tae-Rim Choi ${ }^{1}$, Ye-Lim Park ${ }^{1}$, Jun Young Park ${ }^{1}$, Hun-suk Song ${ }^{1}$, \\ Hyun-Joong Kim ${ }^{1}$, Sun Mi Lee ${ }^{1}$, Sol Lee Park ${ }^{1}$, Hye Soo Lee ${ }^{1}$, Shashi Bhatia ${ }^{1}$, Ranjit \\ Gurav $^{1}$, and Yung-Hun Yang ${ }^{1}$ \\ ${ }^{1}$ Konkuk University
}

April 28, 2020

\begin{abstract}
Pipecolic acid, a non-proteinogenic amino acid, is a metabolite in lysine metabolism and a key chiral precursor in local anesthesia and macrolide antibiotics. To replace the environmentally unfriendly chemical production or preparation procedure of pipecolic acid, many biological synthetic routes have been studied for a long time. Among them, synthesis by lysine cyclodeaminase (LCD), encoded by pipA, has several advantages, including stability of enzyme activity and NAD+ self-regeneration. Thus, we selected this enzyme for pipecolic acid biosynthesis in a whole-cell bioconversion. To construct a robust pipecolic acid production system, we investigated important conditions including expression vector, strain, culture conditions, and other reaction parameters. The most important factors were introduction of multiple pipA genes into the whole-cell system and control of agitation. As a result, we produced $724 \mathrm{mM}$ pipecolic acid $(72.4 \%$ conversion), and the productivity was $0.78 \mathrm{~g} / \mathrm{L} / \mathrm{h}$ from $1 \mathrm{M}$ L-lysine after 5 days. This is the highest production reported to date.
\end{abstract}

\section{Enhancement of pipecolic acid production by the expression of multiple lysine cyclodeaminase in the Escherichia coli whole-cell system}

Yeong-Hoon Han, Tae-Rim Choi, Ye-Lim Park, Jun Young Park, Hun-Suk Song, Hyun-Joong Kim, Sun Mi Lee, Sol Lee Park, Hye Soo Lee, Shashi Kant Bhatia, Ranjit Gurav, Yung-Hun Yang*

Department of Biological Engineering, College of Engineering, Konkuk University, 1 Hwayang-dong, Gwangjin$\mathrm{gu}$, Seoul 05029, Republic of Korea

*Corresponding author (E-mail:seokor@konkuk.ac.kr)

Running title: Reinforced-LCD improves pipecolic acid production

\section{ABSTRACT}

Pipecolic acid, a non-proteinogenic amino acid, is a metabolite in lysine metabolism and a key chiral precursor in local anesthesia and macrolide antibiotics. To replace the environmentally unfriendly chemical production or preparation procedure of pipecolic acid, many biological synthetic routes have been studied for a long time. Among them, synthesis by lysine cyclodeaminase (LCD), encoded by pip $A$, has several advantages, including stability of enzyme activity and $\mathrm{NAD}^{+}$self-regeneration. Thus, we selected this enzyme for pipecolic acid biosynthesis in a whole-cell bioconversion. To construct a robust pipecolic acid production system, we investigated important conditions including expression vector, strain, culture conditions, and other reaction parameters. The most important factors were introduction of multiple pipA genes into the whole-cell system 
and control of agitation. As a result, we produced $724 \mathrm{mM}$ pipecolic acid $(72.4 \%$ conversion), and the productivity was $0.78 \mathrm{~g} / \mathrm{L} / \mathrm{h}$ from $1 \mathrm{M}$ l-lysine after 5 days. This is the highest production reported to date.

Keywords : pipecolic acid (1-PA), pharmaceutical precursor, whole-cell bioconversion, lysine cyclodeaminse (LCD), reinforced enzyme

\section{Introduction}

l-pipecolic acid (l-PA), a non-proteinogenic compound, is a precursor for ropivacaine, bupivacaine, and chloroprocaine, which are widely used in local anesthetics. l-PA is also a precursor for many macrolidepipecolate natural products including rapamycin, tacrolimus (FK-506), and ascomycin (FK-520), which are indispensable immunosuppressors in the clinic. Furthermore, l-PA is a precursor for the anticancer agent VX-710, piperidine alkaloids, and peptide antibiotics (Cheng et al., 2018; Gatto, Boyne, Kelleher, \& Walsh, 2006; Y. H. Kim et al., 2014; Muramatsu et al., 2006; Pérez-García, Max Risse, Friehs, \& Wendisch, 2017; Tani et al., 2015; Ying et al., 2017). l-PA is a key chiral intermediate in the synthesis of many important drugs as mentioned above.

Chirality, which is naturally determined in organisms, plays a key role in the pharmaceutical, agricultural, and chemical industries. Especially in the pharmaceutical industry, production and preparation of single enantiomers from chiral intermediates are important, since chiral drugs account for more than half of the drugs produced (Ying et al., 2017). Similar to the preparation of many other enantiomeric organic compounds, a pure enantiomer of l-PA has been prepared by stereoselective transformation, biosynthesis, and chemical procedures, including resolution of racemates and diastereoselective and enantioselective syntheses (Fujii, Aritoku, Agematu, \& TSUNEKAWA, 2002; Tani et al., 2015; Ying et al., 2015). However, the chemical procedures for commercial-scale preparation of l-PA are complex, tedious, expensive, low-yielding, and environmentally unfriendly (Cheng et al., 2018; Ying et al., 2017; Ying et al., 2015). Compared to chemical methods, biosynthesis of drug-related chiral intermediates is a more environmentally friendly approach for the preparation of affordable pharmaceuticals with higher efficiency (Ying et al., 2017). Since the biological activity of these compounds is dependent on the stereochemistry, there is an increasing demand for an efficient and applicable method to synthesize enantiomerically pure l-PA.

Previous studies have shown two basic routes from l-lysine to l-PA: the d-1-piperidine-2-carboxylic acid (P2C) pathway and the d-1-piperidine-6-carboxylic acid (P6C) pathway (Fujii, Mukaihara, Agematu, \& Tsunekawa, 2002; He, 2006; Ying et al., 2017). In the P2C pathway, the $\alpha$-amino group of l-lysine is lost, and the $\varepsilon$-nitrogen is incorporated into l-PA. In the P6C pathway, the $\varepsilon$-nitrogen is lost, and the $\alpha$-nitrogen is incorporated into l-PA (Ying et al., 2017). Typically, five major steps are involved in these two pathways (Fig. 1). The first requires apoptosis-inducing protein (rAIP) and P2C reductase (DpkA) (Cheng et al., 2018; Muramatsu et al., 2006; Tani et al., 2015). The second belonged to P2C pathway involves the enzymes aminotransferase AGD2-like defense response protein 1 (ALD1) and systemic acquired resistance- deficient 4 (SARD4) (Ding et al., 2016; Hartmann et al., 2017; Xu et al., 2018). The third one requires lysine cyclodeaminase (LCD), and this enzyme is the focus of this study. LCD alone can directly catalyze the conversion of l-lysine to l-PA through the P6C pathway and has advantages, including being more suitable for complicated upstream processes because of its simplicity (Cheng et al., 2018; Gatto et al., 2006; Tsotsou \& Barbirato, 2007; Ying et al., 2017; Ying et al., 2018; Ying et al., 2015). The fourth one involves l-lysine 6aminotransferase (LAT) fromFlavobacterium lutescens (IFO 3084 strain) and pyrroline-5-carboxylate (P5C) reductase encoded by proC gene of $E$. coli through the P6C pathway (Fujii, Aritoku, et al., 2002; Fujii, Mukaihara, et al., 2002). Finally, another route in the P6C pathway using P5C reductase requires lysine dehydrogenase (LysDH) from Silicibacter pomeroyi . In this route, LysDH converts l-lysine to $\alpha$-aminoadipic semialdehyde. Then, $\alpha$-aminoadipic semialdehyde is spontaneously transformed to P6C by cyclization with dehydration (Pérez-García et al., 2017; Pérez-García, Peters-Wendisch, \& Wendisch, 2016).

Up to now, two of the five enzymes, rAIP/DpkA and LCD, have been used in high production systems (Table 1). Tani et al. (2015) used purified rAIP/DpkA enzymes to produce $45.1 \mathrm{~g} / \mathrm{L}$ of pipecolic acid with racemic catalysis. With the same enzymes, Cheng et al. (2018) applied the fed-batch fermentation system 
using recombinant cadaverine decarboxylase (cadA)-knockout strains containing lysine permease (LysP) and glucose dehydrogenase $(\mathrm{GDH})$ and reported a titer of $46.7 \mathrm{~g} / \mathrm{L}$ pipecolic acid from l-lysine $\mathrm{HCl}$ solution. Ying et al. (2015) produced $17.25 \mathrm{~g} / \mathrm{L}$ of pipecolic acid using $E$. coli with LCD as the whole-cell biocatalyst and demonstrated that it has sustained enzymatic activity and self-regenerates $\mathrm{NAD}^{+}$by cyclization, offering a better alternative to the two-step enzymatic process with rAIP and DpkA. To overcome substrate inhibition, they manipulated the enzyme structure related with the substrate and product delivery tunnels via saturation mutagenesis, resulting in $73.4 \mathrm{~g} / \mathrm{L}$ of pipecolic acid using whole-cell reaction (Ying et al., 2019).

In this study, we selected LCD because of its advantages for l-PA production and used a reinforced whole-cell system by introducing multiple copies of pipA to improve overall conversion without any complex manipulation of LCD itself. After optimization of the reinforced whole-cell reaction, we report the highest titer (93.5 $\mathrm{g} / \mathrm{L}$ ) to date, increased 5.4-fold over using the same LCD reported previously. A major factor improving l-PA production in the whole-cell system was fine-tuning of gene copy numbers.

\section{Materials and methods}

\subsection{Chemical reagents}

The chemical reagents used in this study (l-lysine monohydrochloride, pyridine, and sodium hydroxide) were obtained from Sigma-Aldrich (USA). The derivatization reagent, ethyl chloroformate (ECF), was purchased from Fluka (Japan). $\mathrm{NaHCO}_{3}$ was purchased from Samchun (Korea). Methanol and chloroform were obtained from Fisher (Korea). Triton X-100 and sodium phosphate (Monobasic and dibasic, anhydrous) were purchased from Biosesang (Korea).

\subsection{Plasmid construction, strains, media, and culture conditions}

E. coli DH5 $\alpha$ was used as the host for genetic engineering. Cells were cultured and maintained at $37{ }^{\circ} \mathrm{C}$ in lysogeny broth (LB) containing $10 \mathrm{~g} / \mathrm{L}$ tryptone, $5 \mathrm{~g} / \mathrm{L}$ yeast extract, and $5 \mathrm{~g} / \mathrm{L}$ sodium chloride. Antibiotics were added as required $(50 \mu \mathrm{g} / \mathrm{mL}$ kanamycin, $100 \mu \mathrm{g} / \mathrm{mL}$ spectinomycin, $35 \mu \mathrm{g} / \mathrm{mL}$ chloramphenicol, and $50 \mu \mathrm{g} / \mathrm{mL}$ ampicillin).

pipA encoding LCD was amplified from Streptomyces pristinaespiralis ATCC25486 chromosomal DNA as the PCR template. PCR products were inserted into the MCS-1 site of pCDF duet-1 vector via digestion with BamHI and SacI, and into the MCS-2 site via digestion with MfeI and KpnI. The constructed plasmids were prepared and transformed into E. coli BL21 Star (DE3) competent cells for the whole-cell reaction. Engineered plasmids were confirmed with sequencing (Cosmo Genetech, Seoul, Korea). Bacterial strain and plasmid information is listed in Table 2.

E. coli BL21 Star (DE3) bacteria harboring the constructed plasmid were cultured at $37{ }^{\circ} \mathrm{C}$ in a shaking incubator (Han-Beak Science Co., Bucheon, Gyeonggi-do, Korea) at $200 \mathrm{rpm}$. The culture was incubated overnight in $5 \mathrm{~mL}$ LB medium with appropriate antibiotics for plasmid stability in a $14 \mathrm{~mL}$ round-bottom tube. The incubated cells were added to $50 \mathrm{~mL}$ terrific broth (TB) with antibiotics in a $250 \mathrm{~mL}$ baffled Erlenmeyer flask and incubated at $37 \operatorname{deg} \mathrm{C}$ with shaking. At an $\mathrm{OD}_{600}$ of $0.6-0.7$, protein expression was induced with $0.1 \mathrm{mM}$ isopropyl $\beta$-D-1-thiogalactopyranoside (IPTG), and the temperature was decreased to $30{ }^{\circ} \mathrm{C}$. After $16 \mathrm{~h}$, the cultured cells were harvested, centrifuged at $5,500 \mathrm{rpm}$ for $10 \mathrm{~min}$ at $4{ }^{\circ} \mathrm{C}$, washed, and resuspended with deionized water to an $\mathrm{OD}_{600}$ of 100.

\subsection{Whole-cell reaction}

The harvested BL21 Star (DE3) cells expressing LCD were used for the whole-cell reaction. For l-PA production, $200 \mathrm{mM}$ l-lysine was used as substrate, and $150 \mathrm{mM}$ potassium phosphate buffer $(\mathrm{pH} 7)$ was used to buffer the mixture. To enhance cell permeability, $0.1 \%$ triton $\mathrm{X}-100$ was added. $\mathrm{FeSO}_{4}$ at $20 \mathrm{mM}$ was added as source of iron. Distilled water was added to the reaction mixture containing harvested cells with an $\mathrm{OD}_{600}$ of 50 to prepare a total volume of $400 \mu \mathrm{L}$. The mixture was titrated to $\mathrm{pH} 7.5$ with $2 \mathrm{~N} \mathrm{NaOH}$. The reaction was conducted at $37^{\circ} \mathrm{C}$ with gentle shaking (40-50 rpm). After reaction, $100 \mu \mathrm{L}$ of each sample 
was collected and heated at $95{ }^{\circ} \mathrm{C}$ for 5 min to complete the reaction. Inactivated cells were eliminated by centrifugation at 13,000 rpm, and the supernatant was diluted to an appropriate concentration for analysis.

\subsection{Analytical methods}

For derivatization, samples containing carboxylic acid or amine functional groups, such as l-PA, were diluted to less than $10 \mathrm{mM}$, and $100 \mu \mathrm{L}$ of the diluted samples was mixed with $400 \mu \mathrm{L}$ of $1 \mathrm{~N} \mathrm{NaOH}, 66 \mu \mathrm{L}$ of pyridine, and $334 \mu \mathrm{L}$ of ethanol by gentle shaking. Then, $80 \mu \mathrm{L}$ of ECF was added to the mixture, followed by vortexing for $30 \mathrm{~s}$. To complete the derivatization and separate the layers, $800 \mu \mathrm{L}$ of $30 \mathrm{mM} \mathrm{NaHCO}_{3}$ and chloroform were added into the derivatized mixture, followed by shaking for $10 \mathrm{~s}$. After settling, the bottom layer was filtered using a $0.2 \mu \mathrm{m}$ syringe filter. All reactions were performed at room temperature (Yi et al., 2015).

The derivatized samples were analyzed by gas chromatography-mass spectrometry (GC-MS) (Perkin Elmer Clarus $680 \mathrm{GC}$ system and Clarus SQ 8T MS system). Sample solution $(1 \mu \mathrm{L})$ was injected into an Elite $5 \mathrm{MS}$ column $(30 \mathrm{~m} \times 0.25 \mathrm{~mm} \times 0.25 \mu \mathrm{m}$ film thickness $)$ using helium as a carrier gas at a flow rate of 1 $\mathrm{mL} / \mathrm{min}$. The initial oven temperature was set at $120{ }^{\circ} \mathrm{C}$ for $5 \mathrm{~min}$ and increased to $200{ }^{\circ} \mathrm{C}$ in increments of $5{ }^{\circ} \mathrm{C} / \mathrm{min}$. When the temperature reached $200{ }^{\circ} \mathrm{C}$, the rate was changed to $2{ }^{\circ} \mathrm{C} / \mathrm{min}$. After the temperature increased to $220^{\circ} \mathrm{C}$, the rate was set to $10{ }^{\circ} \mathrm{C} / \mathrm{min}$. It was finished when the oven temperature reached 300 ${ }^{\circ} \mathrm{C}$. The temperature of the injector and ion source were set to $270{ }^{\circ} \mathrm{C}$ and $250{ }^{\circ} \mathrm{C}$, respectively. The electron energy was $70 \mathrm{eV}$. The mass spectrometer was operated in full scan mode from 45 to $400 \mathrm{~m} / \mathrm{z}$, with a scan time of $0.2 \mathrm{~s}$.

\section{Results and Discussion}

\subsection{Construction of whole-cell systems for l-PA production and selection of expression strain and vector}

To construct the l-PA production system, pipA fromStreptomyces pristinaespiralis encoding LCD was introduced into the MCS-1 site of each duet vector. pCDF duet-1, pRSF duet-1, pACYC duet-1, and pET duet-1 were used as expression vectors. To identify the most effective expression vector, the $E$. coli BL21 (DE3) protein expression strain was transformed with these recombinant vectors. Expression of pipA was induced, and the whole-cell reaction was performed directly. In the whole-cell reaction, $200 \mathrm{mM}$ l-lysine was used as substrate, and the reaction proceeded at $37^{\circ} \mathrm{C}$ for 1 day. Only the strains containing the pCDF duet- 1 and pET duet-1 vector produced l-PA at $50 \mathrm{mM}$ and $11 \mathrm{mM}$, respectively (Fig. 2A). l-PA was not produced from the other strains. pCDF duet-1 was more efficient than pET duet-1, with about 3.3-fold higher productivity. Thus, the pCDF vector was deemed the most suitable for l-PA production. Using this expression vector, other DE3 expression strains were tested. As the control strain, BL21 was compared to BW25113 and BL21 Star (DE3). As shown in Figure 2B, production in the Star strain was 1.5-fold higher than the BL21 control strain. The BW25113 strain also produced l-PA; however, conversion was lower than the other strains. As a result, the Star strain containing the recombinant pCDF duet-1 (yhPA001) was used for further experiments.

\subsection{Effect of tandem gene repeats on bioconversion of l-PA}

In a previous study, LCD in the whole-cell system produced $133 \mathrm{mM}$ l-PA from l-lysine (Ying et al., 2015). Combination of expression vectors or reinforced whole cells, which contain another plasmid with same gene or a duplicate copy of the gene in the same plasmid, improves rapid production (Y. G. Hong et al., 2019; J. Kim et al., 2017). Thus, we combined the effective expression vectors and performed additional gene manipulation (Fig. 3). We constructed the Star strain harboring recombinant pET duet-1::pipA (yhPA002) and the Star strain harboring pCDF duet-1::pipA and pET duet-1::pipA(yhPA003). Comparing these strains, the yhPA001 (pCDF duet-1::pipA ) strain had the highest conversion. Unexpectedly, yhPA003 (pET duet$1:: p i p A+$ pCDF duet-1::pipA ), which carries an extra vector, was less productive than yhPA001. To prepare other combinations for the reinforced system, we inserted pipAinto the MCS-2 site of each recombinant vector. A reinforced gene denotes that two or more copies were introduced into an expression vector for overexpression (Y. G. Hong et al., 2019), and this reinforced genetic material was used for the transformation of expression strains which were named yhPA004 (pCDF duet-1::pipA ::pipA), yhPA005 (pET duet-1::pipA 
::pipA ), and yhPA006 (pET duet-1::pipA ::pipA + pCDF duet-1::pipA ::pipA). The yhPA004 strain had the highest production among all engineered strains. The yhPA006 strain containing two reinforced two vectors had a lower conversion than the yhPA004 with single vector. To determine whether chaperones could improve production, we prepared whole cells with different chaperones and conducted the whole-cell reaction (Supplementary Fig. 1A). The yhPA004 strain was used as the control, and other strains were transformed with chaperone vectors, including pGro7, pTF16, and pKJE7 (Nishihara, Kanemori, Kitagawa, Yanagi, \& Yura, 1998; Tian, Chen, Yu, \& Shen, 2016). However, the activity of the control enzyme was higher than the strains expressing the chaperones. We also tested whether lysine permease improved lysine permeability. lys $P$ was introduced and expressed in the intact expression vector (pET duet-1) to avoid overlapping vector use (Li et al., 2016; Steffes, Ellis, Wu, \& Rosen, 1992). However, additional expression did not improve production (Supplementary Fig. 1B).

\subsection{Optimization of culture conditions for improving enzyme activity}

To improve enzyme activity, it is needed to determine the optimal culture conditions, including medium, growth temperature, and IPTG concentration, leading to regulation of expression level or condition to maximize the enzyme activity. Generally, LB broth was used for E. coli fermentation. However, this broth contains relatively low nutrient concentration. Since terrific broth (TB), super broth (SB), and $2 \times$ YT broth are commonly used as highly enriched media, these were investigated compared to LB broth to get enhanced enzyme activity and cell growth (Y. G. Hong et al., 2019; J. Kim et al., 2017). With the reinforced enzyme, the yhPA004 strain was cultured in the four different broths. After $0.1 \mathrm{mM}$ IPTG induction, these were incubated at $25{ }^{\circ} \mathrm{C}$. The whole-cell reaction was conducted as in the previous experiment. To measure the cell dry weight, aliquots of $5 \mathrm{~mL}$ were collected from the culture media and freeze-dried. LCD activity in whole cells harvested from TB broth was two-fold higher than from LB broth. The activity from SB broth and $2 \times$ YT broth was also higher than from LB, however, lower than from TB broth (Fig. 4A). Likewise, the cell dry weight from TB broth was highest at $2.4 \mathrm{~g} / \mathrm{L}$ and 2.5 -fold higher than that from LB (Fig. 4B). Based on these results, TB broth was determined to be the best induction media for the yhPA004 strain.

Overexpression of exogenous genes with plasmid system, especially when regulated by IPTG, is strongly affected by growth temperature and IPTG concentration (Baim, Labow, Levine, \& Shenk, 1991; HugouvieuxCotte-Pattat, Dominguez, \& Robert-Baudouy, 1992; Tobe et al., 1991). Thus, we investigated optimal induction conditions using TB broth. First, we investigated the induction temperature by incubating the cultures at $20{ }^{\circ} \mathrm{C}, 25{ }^{\circ} \mathrm{C}, 30{ }^{\circ} \mathrm{C}$, or $37{ }^{\circ} \mathrm{C}$ after adding $0.1 \mathrm{mM}$ IPTG. Whole-cell reactions were conducted using the same conditions as in the previous experiment. l-PA production increased as the induction temperature increased up to $30{ }^{\circ} \mathrm{C}$, which showed the highest activity (Fig. 4C). Enzyme activity induced in $37^{\circ} \mathrm{C}$ was the lowest of all tested temperatures. Optimal IPTG concentration was also investigated. After IPTG was added (0.01 mM, $0.05 \mathrm{mM}, 0.1 \mathrm{mM}, 0.5 \mathrm{mM}$, or $1 \mathrm{mM})$, expression was induced at $30{ }^{\circ} \mathrm{C}$. We determined the best IPTG concentration for LCD expression was $0.1 \mathrm{mM}$, demonstrating that excessive or insufficient IPTG concentration decreased enzyme activity (Fig. 4D). Based on these experiments for efficient l-PA production, the yhPA004 strain was cultured in TB broth and induced with $0.1 \mathrm{mM}$ IPTG at $30^{\circ} \mathrm{C}$.

\subsection{Effect of agitation, buffer, and metal ions in the whole-cell reaction}

In previous studies, optimal conditions for LCD activity, such as $\mathrm{pH}$, temperature, and substrate concentration (l-lysine), were reported, and exogenous addition of iron (II) sulfate, $\mathrm{NAD}^{+}$, and detergent such as Triton X-100 improved productivity (Ying et al., 2015). Herein, we tested whether additional conditions including agitation, buffer concentration, and metal ions affected productivity (Y. G. Hong et al., 2019; Moon et al., 2019). To test the effect of agitation, the whole-cell reaction for l-PA production was carried out for $48 \mathrm{~h}$, and agitating the reaction was compared to the settling method. Performing the reaction with agitation increased l-PA production by two-fold compared to using the settling method (Fig. 5A). The two-fold difference in conversion could be observed from early in the reaction. Therefore, adding agitation improves l-PA production in the whole-cell system.

In the whole-cell reaction, $\mathrm{pH} 7.5$ is optimal for LCD enzyme activity, and l-PA increases the acidity of 
the mixture. Phosphate buffer $(\mathrm{pH} 7)$ was used to prevent the decrease in $\mathrm{pH}$ owing to the production of l-PA, which is important to produce high concentration l-PA. The whole-cell reaction was conducted with different buffer concentrations compared to the control sample without buffer. Addition of buffer up to $150 \mathrm{mM}$ increased l-PA production, and increasing the buffer concentration over $200 \mathrm{mM}$ did not affect production (Fig. 5B). Therefore, we chose $150 \mathrm{mM}$ phosphate buffer for subsequent reactions.

To investigate the effect of metal ions, different metal ions were tested in the whole-cell reaction. Only $\mathrm{FeCl}_{2}$ enhanced LCD enzyme activity, while other metals decreased activity (Fig. 5C). In the first test, iron chloride was used, and we wanted to investigate whether the form of the iron salt had an effect. Both the chloride and sulfate forms can improve the enzyme activity. The chloride form showed 1.3-fold higher production, and the sulfate form showed 1.45-fold of the control (Fig. 5D). When the optimal iron concentration was tested, the highest conversion was observed with $20 \mathrm{mM}$ iron sulfate (data not shown). According to previous literature on LCD, $\mathrm{NAD}^{+}$increases enzyme activity as a cofactor (Gatto et al., 2006; Ying et al., 2017; Ying et al., 2015). However, in our system, $\mathrm{NAD}^{+}$addition did not improve whole-cell conversion compared to control (Supplementary Fig. 2).

\subsection{Time-dependent l-PA production with different substrate concentrations}

After optimization, we conducted the whole-cell reaction with the optimal conditions (strain: yhPA004; fermentation conditions: TB broth, $30{ }^{\circ} \mathrm{C}, 0.1 \mathrm{mM}$ IPTG; reaction conditions: $\mathrm{pH}$ 7.5, $150 \mathrm{mM}$ phosphate buffer, $20 \mathrm{mM} \mathrm{FeSO}_{4}$, and $0.1 \%$ Triton X-100 with gently mixing), and we monitored the time-dependent l-PA production according to l-lysine concentrations for 6 days. The l-lysine concentration ranged from $400 \mathrm{mM}$ to $1 \mathrm{M}$. l-PA production increased for 5 days for all substrate concentrations and showed the highest conversion at day 6, except for $1 \mathrm{M}$ l-lysine which showed the highest production at day 5 (Fig. 6A). The highest production and conversion from each concentration are shown in Figure 6B. Production was $317 \mathrm{mM}, 473$ $\mathrm{mM}, 673 \mathrm{mM}$, and $724 \mathrm{mM}$ from $400 \mathrm{mM}, 600 \mathrm{mM}, 800 \mathrm{mM}$, and $1 \mathrm{M}$ l-lysine, respectively, and conversions were $79.3 \%, 78.8 \%, 84.1 \%$, and $72.4 \%$, respectively. The highest conversion yield was demonstrated with $800 \mathrm{mM}$ l-lysine (84.1\%); however, the concentration of l-PA produced was highest with $1 \mathrm{M}$ l-lysine (93.5 $\mathrm{g} / \mathrm{L} ; 72.4 \%$ conversion). Comparing the productivity between $800 \mathrm{mM}$ and $1 \mathrm{M}$ l-lysine, productivity was $0.63 \mathrm{~g} / \mathrm{L} / \mathrm{h}$ from $800 \mathrm{mM}$ and $0.78 \mathrm{~g} / \mathrm{L} / \mathrm{h}$ from $1 \mathrm{M}$ l-lysine. As mentioned above, agitation was essential to enhance LCD activity in this system. Faster agitation speed promoted higher productivity; however, vigorous agitation (1300 rpm) caused whole-cell activity to be lost after 2 days (Supplementary Fig. 3).

\section{Conclusions}

Present biochemical production by microbial biotransformation has improved with strain development techniques and process engineering. In tandem, amino acid-based bioconversion has been used to make biotransformation more efficient and economical because amino acids such as l-lysine and l-glutamate can be produced affordably on a large scale (Georgi, Rittmann, \& Wendisch, 2005; Y.-G. Hong et al., 2018; H. J. Kim et al., 2015; H. T. Kim et al., 2019; J.-H. Kim et al., 2017; Kimura, 2003; Shin et al., 2018; Stansen et al., 2005; Yang et al., 2019; Yang et al., 2020). Starting from these compounds, we can avoid the long, complex pathway from glucose to reach the final product. In addition, we can avoid individual strain construction, and we can overcome the low productivity of a precursor or intermediate from a general strain, without identifying a new pathway. In practice, high-producing strains are not widely accessible, and there is a large difference between the high-producing strains and a newly developed strain. Typically, new pathways or strains will have a lower titer than expected, and it does not necessarily solve the problems needed to develop a high-producing strain. As a result, biochemical production starting from highly accessible chemicals with bioconversion is in high demand. In addition, we can focus our efforts on essential processes to improve the pathway and final product. There are several successful examples of bioconversion including cadaverine production from l-lysine (Huang et al., 2020; H. J. Kim et al., 2015; J.-H. Kim et al., 2016; J.-H. Kim et al., 2017; Rui et al., 2020), glutaric acid production from l-lysine (Y.-G. Hong et al., 2018; Yang et al., 2019; Yang et al., 2020), and $\gamma$-aminobutyric acid production from l-glutamate (Ke et al., 2016; Park et al., 2013; Plokhov et al., 2000; Yuan et al., 2019). 
For these reasons, we have continued to develop different bioconversion systems from readily available chemicals and optimized whole-cell reactions resulting in the highest titer and increase of productivity. In addition to changing the starting material, we used easily accessible tools by comparing accessible plasmids and reinforced whole-cell systems by incorporating tandem genes. The simplicity of techniques in this study demonstrates that productivity could be improved in a straightforward manner. Furthermore, this study details many parameters to adjust for large production and raises several questions for studies in the near future.

In our approach, we constructed the l-PA production system with the reinforced gene and optimized culture conditions including medium composition, temperature, IPTG concentration, agitation speed, metal ion and buffer concentration. As a result, we produced $93.5 \mathrm{~g} / \mathrm{L}$ l-PA and improved production more than 5 -fold over that in previous studies. Furthermore, productivity from $1 \mathrm{M}$ l-lysine (monohydrochloride) was $0.78 \mathrm{~g} / \mathrm{L} / \mathrm{h}$ by modifying gene copies and systematically optimizing reaction parameters. l-lysine monohydrochloride is much cheaper and more soluble than l-lysine. Further efforts to stabilize the system for longer times or to shorten the reaction and studies on l-PA recovery from reaction solution will continue to improve l-PA production.

Acknowledgments This study was supported by the National Research Foundation of Korea (NRF) (NRF2019R1F1A1058805 and NRF-2019M3E6A1103979), Research Program to solve social issues of the National Research Foundation of Korea (NRF) funded by the Ministry of Science and ICT (2017M3A9E4077234). This work was also supported by R\&D Program of MOTIE/KEIT (10067772) and by R\&D Program for Forest Science Technology (Project No. 2020261C10-2022-AC02) provided by Korea Forest Service (Korea Forestry Promotion Institute). Consulting service provided by the Microbial Carbohydrate Resource Bank (MCRB, Seoul, Korea) is highly appreciated.

\section{Funding}

\section{Declarations of interest : none.}

\section{References}

Baim, S. B., Labow, M. A., Levine, A. J., \& Shenk, T. (1991). A chimeric mammalian transactivator based on the lac repressor that is regulated by temperature and isopropyl beta-D-thiogalactopyranoside. Proceedings of the National Academy of Sciences, 88(12), 5072-5076. Cheng, J., Huang, Y., Mi, L., Chen, W., Wang, D., \& Wang, Q. (2018). An economically and environmentally acceptable synthesis of chiral drug intermediate l-pipecolic acid from biomass-derived lysine via artificially engineered microbes. Journal of industrial microbiology 83 biotechnology, 45(6), 405-415. Ding, P., Rekhter, D., Ding, Y., Feussner, K., Busta, L., Haroth, S., . . . Feussner, I. (2016). Characterization of a pipecolic acid biosynthesis pathway required for systemic acquired resistance. The Plant Cell, 28(10), 2603-2615. Fujii, T., Aritoku, Y., Agematu, H., \& TSUNEKAWA, H. (2002). Increase in the rate of L-pipecolic acid production using lat-expressing Escherichia coli by lysP and yeiE amplification. Bioscience, biotechnology, and biochemistry, 66 (9), 19811984. Fujii, T., Mukaihara, M., Agematu, H., \& Tsunekawa, H. (2002). Biotransformation of L-lysine to L-pipecolic acid catalyzed by L-lysine 6 -aminotransferase and pyrroline-5-carboxylate reductase. Bioscience, biotechnology, and biochemistry, 66(3), 622-627. Gatto, G. J., Boyne, M. T., Kelleher, N. L., \& Walsh, C. T. (2006). Biosynthesis of pipecolic acid by RapL, a lysine cyclodeaminase encoded in the rapamycin gene cluster.Journal of the American Chemical Society, 128(11), 3838-3847. Georgi, T., Rittmann, D., \& Wendisch, V. F. (2005). Lysine and glutamate production by Corynebacterium glutamicum on glucose, fructose and sucrose: roles of malic enzyme and fructose-1, 6-bisphosphatase. Metabolic engineering, 7(4), 291-301. Hartmann, M., Kim, D., Bernsdorff, F., Ajami-Rashidi, Z., Scholten, N., Schreiber, S., . . . Zeier, J. (2017). Biochemical principles and functional aspects of pipecolic acid biosynthesis in plant immunity. Plant physiology, 174(1), 124-153. He, M. (2006). Pipecolic acid in microbes: biosynthetic routes and enzymes. Journal of Industrial Microbiology and Biotechnology, 33(6), 401-407. Hong, Y.-G., Moon, Y.-M., Hong, J.-W., No, S.-Y., Choi, T.-R., Jung, H.-R., . . . Park, K.-M. (2018). Production of glutaric acid from 5-aminovaleric acid using Escherichia coli whole cell bio-catalyst overexpressing GabTD from Bacillus 
subtilis. Enzyme and microbial technology, 118, 57-65. Hong, Y. G., Moon, Y. M., Choi, T. R., Jung, H. R., Yang, S. Y., Ahn, J. O., . . . Bhatia, S. K. (2019). Enhanced production of glutaric acid by NADH oxidase and GabD-reinforced bioconversion from L-lysine. Biotechnology and bioengineering. Huang, C.-Y., Ting, W.-W., Chen, Y.-C., Wu, P.-Y., Dong, C.-D., Huang, S.-F., . . . Chang, J.-S. (2020). Facilitating the enzymatic conversion of lysineto cadaverine in engineered Escherichia coli with metabolic regulation by genes deletion.Biochemical Engineering Journal, 156, 107514. Hugouvieux-Cotte-Pattat, N., Dominguez, H., \& Robert-Baudouy, J. (1992). Environmental conditions affect transcription of the pectinase genes of Erwinia chrysanthemi 3937. Journal of bacteriology, 174(23), 7807-7818. Ke, C., Yang, X., Rao, H., Zeng, W., Hu, M., Tao, Y., \& Huang, J. (2016). Whole-cell conversion of L-glutamic acid into gamma-aminobutyric acid by metabolically engineered Escherichia coli. Springerplus, 5(1), 591. Kim, H. J., Kim, Y. H., Shin, J.-H., Bhatia, S. K., Sathiyanarayanan, G., Seo, H.-M., . . . Park, K. (2015). Optimization of direct lysine decarboxylase biotransformation for cadaverine production with whole-cell biocatalysts at high lysine concentration. J. Microbiol. Biotechnol, 25(7), 1108-1113. Kim, H. T., Baritugo, K.-A., Hyun, S. M., Khang, T. U., Sohn, Y. J., Kang, K. H., . . . Kim, I.-K. (2019). Development of Metabolically Engineered Corynebacterium glutamicum for Enhanced Production of Cadaverine and Its Use for the Synthesis of BioPolyamide 510. ACS Sustainable Chemistry \& Engineering. Kim, J.-H., Kim, H. J., Kim, Y. H., Jeon, J. M., Song, H. S., Kim, J., . . . Park, K. M. (2016). Functional study of lysine decarboxylases from Klebsiella pneumoniae in Escherichia coli and application of whole cell bioconversion for cadaverine production. $J$. Microbiol. Biotechnol, 26(9), 1586-1592. Kim, J.-H., Kim, J., Kim, H.-J., Sathiyanarayanan, G., Bhatia, S. K., Song, H.-S., . . . Yang, Y.-H. (2017). Biotransformation of pyridoxal 5'-phosphate from pyridoxal by pyridoxal kinase ( $\mathrm{pdxY})$ to support cadaverine production in Escherichia coli. Enzyme and microbial technology, 104, 9-15. Kim, J., Seo, H.-M., Bhatia, S. K., Song, H.-S., Kim, J.-H., Jeon, J.-M., . . . Kim, Y.G. (2017). Production of itaconate by whole-cell bioconversion of citrate mediated by expression of multiple cis-aconitate decarboxylase (cadA) genes in Escherichia coli. Scientific reports, 7(1), 1-9. Kim, Y. H., Park, B. S., Bhatia, S. K., Seo, H.-M., Jeon, J.-M., Kim, H.-J., . . . Park, H.-Y. (2014). Production of rapamycin in Streptomyces hygroscopicus from glycerol-based media optimized by systemic methodology. J Microbiol Biotechnol, 24(10), 1319-1326. Kimura, E. (2003). Metabolic engineering of glutamate production. In Microbial Production of l-Amino Acids (pp. 37-57): Springer. Li, Z., Xu, J., Jiang, T., Ge, Y., Liu, P., Zhang, M., . . . Xu, P. (2016). Overexpression of transport proteins improves the production of 5-aminovalerate from l-lysine in Escherichia coli. Scientific reports, 6, 30884. Moon, Y.-M., Yang, S. Y., Choi, T. R., Jung, H.-R., Song, H.-S., hoon Han, Y., . . . Park, K. (2019). Enhanced production of cadaverine by the addition of hexadecyltrimethylammonium bromide to whole cell system with regeneration of pyridoxal-5'-phosphate and ATP. Enzyme and microbial technology, 127, 58-64. Muramatsu, H., Mihara, H., Yasuda, M., Ueda, M., Kurihara, T., \& Esaki, N. (2006). Enzymatic synthesis of L-pipecolic acid by $\Delta 1-$ piperideine-2-carboxylate reductase from Pseudomonas putida. Bioscience, biotechnology, and biochemistry, 70 (9), 2296-2298. Nishihara, K., Kanemori, M., Kitagawa, M., Yanagi, H., \& Yura, T. (1998). Chaperone coexpression plasmids: Differential and synergistic roles of DnaK-DnaJ-GrpE and GroEL-GroES in assisting folding of an allergen of Japanese cedar pollen, Cryj2, inEscherichia coli. Appl. Environ. Microbiol., 64(5), 1694-1699. Pérez-García, F., Max Risse, J., Friehs, K., \& Wendisch, V. F. (2017). Fermentative production of L-pipecolic acid from glucose and alternative carbon sources.Biotechnology journal, 12(7), 1600646. Perez-Garcia, F., Peters-Wendisch, P., \& Wendisch, V. F. (2016). Engineering Corynebacterium glutamicum for fast production of L-lysine and L-pipecolic acid. Applied microbiology and biotechnology, 100(18), 8075-8090. Park, S. J., Kim, E. Y., Noh, W., Oh, Y. H., Kim, H. Y., Song, B. K., . . . Jegal, J. (2013). Synthesis of nylon 4 from gamma-aminobutyrate (GABA) produced by recombinant Escherichia coli. Bioprocess and biosystems engineering, 36(7), 885-892. Plokhov, A. Y., Gusyatiner, M., Yampolskaya, T., Kaluzhsky, V., Sukhareva, B., \& Schulga, A. (2000). Preparation of $\gamma$-aminobutyric acid using E. coli cells with high activity of glutamate decarboxylase. Applied biochemistry and biotechnology, 88(1-3), 257265. Rui, J., You, S., Zheng, Y., Wang, C., Gao, Y., Zhang, W., . . . He, Z. (2020). High-efficiency and low-cost production of cadaverine from a permeabilized-cell bioconversion by a Lysine-induced engineered Escherichia coli.Bioresource technology, 302, 122844. Shin, J., Joo, J. C., Lee, E., Hyun, S. M., Kim, H. J., Park, S. J., . . . Park, K. (2018). Characterization of a whole-cell biotransformation using a 
constitutive lysine decarboxylase from Escherichia coli for the high-level production of cadaverine from industrial grade L-lysine. Applied biochemistry and biotechnology, 185(4), 909-924. Stansen, C., Uy, D., Delaunay, S., Eggeling, L., Goergen, J.-L., \& Wendisch, V. F. (2005). Characterization of a Corynebacterium glutamicum lactate utilization operon induced during temperature-triggered glutamate production. Appl. Environ. Microbiol., 71(10), 5920-5928. Steffes, C., Ellis, J., Wu, J., \& Rosen, B. P. (1992). The lysP gene encodes the lysine-specific permease.Journal of bacteriology, 174(10), 3242-3249. Tani, Y., Miyake, R., Yukami, R., Dekishima, Y., China, H., Saito, S., . . . Mihara, H. (2015). Functional expression of l-lysine $\alpha$-oxidase from Scomber japonicus in Escherichia coli for one-pot synthesis of l-pipecolic acid from dl-lysine.Applied microbiology and biotechnology, $99(12)$, 5045-5054. Tian, Y., Chen, J., Yu, H., \& Shen, Z. (2016). Overproduction of the Escherichia coli chaperones GroEL-GroES in Rhodococcus ruber improves the activity and stability of cell catalysts harboring a nitrile hydratase. J Microbiol Biotechnol, 26, 337. Tobe, T., Nagai, S., Okada, N., Adter, B., Yoshikawa, M., \& Sasakawa, C. (1991). Temperature-regulated expression of invasion genes in Shigella flexneri is controlled through the transcriptional activation of the virB gene on the large plasmid.Molecular microbiology, 5(4), 887-893. Tsotsou, G. E., \& Barbirato, F. (2007). Biochemical characterisation of recombinant Streptomyces pristinaespiralis L-lysine cyclodeaminase. Biochimie, 89(5), 591-604. Xu, B., Fan, Z., Lei, Y., Ping, Y., Jaisi, A., \& Xiao, Y. (2018). Insights into pipecolic acid biosynthesis in Huperzia serrata. Organic letters, 20(8), 2195-2198. Yang, S.-Y., Choi, T.-R., Jung, H.-R., Park, Y.-L., Han, Y.-H., Song, H.-S., . . . Jeon, W.-Y. (2019). Production of glutaric acid from 5 -aminovaleric acid by robust whole-cell immobilized with polyvinyl alcohol and polyethylene glycol.Enzyme and microbial technology, 128, 72-78. Yang, S.-Y., Choi, T.-R., Jung, H.-R., Park, Y.-L., Han, Y.-H., Song, H.-S., . . . Ahn, J.-O. (2020). Development of glutaric acid production consortium system with $\alpha$-ketoglutaric acid regeneration by glutamate oxidase in Escherichia coli. Enzyme and microbial technology, 133, 109446. Yi, D.-H., Sathiyanarayanan, G., Seo, H. M., Lee, J. H., Kim, H.-J., Kim, Y.-G., . . . Yang, Y.-H. (2015). Linear correlation of aliphatic diamines to response factors by number of carbons in GC-MS. Journal of Industrial and Engineering Chemistry, 30, 322-327. Ying, H., Tao, S., Wang, J., Ma, W., Chen, K., Wang, X., \& Ouyang, P. (2017). Expanding metabolic pathway for de novo biosynthesis of the chiral pharmaceutical intermediate l-pipecolic acid in Escherichia coli. Microbial cell factories, 16(1), 52. Ying, H., Wang, J., Shi, T., Zhao, Y., Ouyang, P., \& Chen, K. (2019). Engineering of lysine cyclodeaminase conformational dynamics for relieving substrate and product inhibitions in the biosynthesis of l-pipecolic acid. Catalysis Science 83 Technology, 9(2), 398-405. Ying, H., Wang, J., Shi, T., Zhao, Y., Wang, X., Ouyang, P., \& Chen, K. (2018). Studies of lysine cyclodeaminase from Streptomyces pristinaespiralis: Insights into the complex transition NAD+ state. Biochemical and biophysical research communications, 495(1), 306-311. Ying, H., Wang, J., Wang, Z., Feng, J., Chen, K., Li, Y., \& Ouyang, P. (2015). Enhanced conversion of l-lysine to l-pipecolic acid using a recombinant Escherichia coli containing lysine cyclodeaminase as whole-cell biocatalyst.Journal of Molecular Catalysis B: Enzymatic, 117, 75-80. Yuan, H., Wang, H., Fidan, O., Qin, Y., Xiao, G., \& Zhan, J. (2019). Identification of new glutamate decarboxylases from Streptomyces for efficient production of $\gamma$-aminobutyric acid in engineered Escherichia coli. Journal of Biological Engineering, 13(1), 24.

\section{Figure legends}

Fig. 1. Biosynthetic routes for converting l-lysine to l-pipecolic acid via P2C and P6C pathways.

Fig. 2. Construction of the pipecolic acid production system with expression combination. (a) Selection of expression vectors and (b) selection of expression strains.

Fig. 3. Comparison between single gene and tandem gene expression with two-vector system. yhPA001 (pCDF duet-1::pipA ), yhPA002 (pET duet-1::pipA), yhPA003 (pCDF duet-1::pipA + pET duet-1::pipA ), yhPA004 (pCDF duet-1::pipA ::pipA), yhPA005 (pET duet-1::pipA ::pipA), and yhPA006 (pCDF duet$1:: p i p A:: p i p A+$ pET duet-1::pipA ::pipA ) were used.

Fig. 4. Optimization of culture conditions affecting enzyme activity: (a) relative enzyme activity with different media, (b) cell dry weight with different media, (c) induction temperature, and (d) IPTG concentration. 
Fig. 5. Effect of (a) agitation, (b) buffer concentration, (c) metal ions, and (d) iron source on whole-cell bioconversion

Fig. 6. Pipecolic acid production according to l-lysine concentration. (a) Time-dependence of pipecolic acid production (b) Production and conversion at the highest point for each.

Table 1

Current high production of pipecolic acid

\begin{tabular}{|c|c|c|c|c|c|c|c|}
\hline Enzyme & $\begin{array}{l}\text { Conversion } \\
\text { process }\end{array}$ & Strategy & Substrate & $\begin{array}{l}\text { L-PA } \\
\text { produc- } \\
\text { tion }\end{array}$ & Conversion & Productivity & Ref \\
\hline $\begin{array}{l}\text { rAIP }+ \\
\text { dpkA }\end{array}$ & $\begin{array}{l}\text { Purified } \\
\text { enzyme }\end{array}$ & $\begin{array}{l}\text { Racemic } \\
\text { catalysis }\end{array}$ & $\begin{array}{l}\text { L-lysine } \\
400 \mathrm{mM}\end{array}$ & $45.1 \mathrm{~g} / \mathrm{L}$ & $87.5 \%$ & $0.98 \mathrm{~g} / \mathrm{L} / \mathrm{h}$ & $\begin{array}{l}\text { Y. Tani et } \\
\text { al (2015) }\end{array}$ \\
\hline $\begin{array}{l}\text { rAIP } \\
\operatorname{dpkA}\end{array}+$ & Fermentation & Fed-batch & $\begin{array}{l}\text { Lysine- } \\
\text { HCl } \\
\text { solution }\end{array}$ & $46.7 \mathrm{~g} / \mathrm{L}$ & - & $2.41 \mathrm{~g} / \mathrm{L} / \mathrm{h}$ & $\begin{array}{l}\text { J. Cheng } \\
\text { et al } \\
(2018)\end{array}$ \\
\hline LCD & Whole cell & Recycling & $\begin{array}{l}\text { L-lysine } \\
170 \mathrm{mM}\end{array}$ & $17.25 \mathrm{~g} / \mathrm{L}$ & $77.7 \%$ & $0.36 \mathrm{~g} / \mathrm{L} / \mathrm{h}$ & $\begin{array}{l}\text { H. Ying et } \\
\text { al (2015) }\end{array}$ \\
\hline LCD & Whole cell & $\begin{array}{l}\text { Mutagenesis } \\
\& \\
\text { Fed-batch }\end{array}$ & $\begin{array}{l}\text { L-lysine } \\
\text { 820mM }\end{array}$ & $73.4 \mathrm{~g} / \mathrm{L}$ & $55.3 \%$ & $0.83 \mathrm{~g} / \mathrm{L} / \mathrm{h}$ & $\begin{array}{l}\text { H. Ying et } \\
\text { al (2018) }\end{array}$ \\
\hline LCD & $\begin{array}{l}\text { Whole } \\
\text { cell }\end{array}$ & $\begin{array}{l}\text { Reinforced } \\
\text { enzyme }\end{array}$ & $\begin{array}{l}\text { Lysine- } \\
\mathrm{HCl} \\
\text { 1M }\end{array}$ & $93.5 \mathrm{~g} / \mathrm{L}$ & $72.4 \%$ & $\begin{array}{l}0.78 \\
\mathrm{~g} / \mathrm{L} / \mathrm{h}\end{array}$ & $\begin{array}{l}\text { In this } \\
\text { study }\end{array}$ \\
\hline
\end{tabular}

Table 2Relevant information of bacterial strains and plasmids

\begin{tabular}{|c|c|c|}
\hline Strain and plasmid & Strain and plasmid & Genotype and strain description \\
\hline Bacterial strains & Bacterial strains & Bacterial strains \\
\hline Escherichia coli $\mathbf{\Delta} \mathbf{H} \mathbf{5} \boldsymbol{\alpha}$ & Escherichia coli $\mathbf{\Delta} \mathbf{H} \mathbf{5} \boldsymbol{\alpha}$ & Escherichia coli $\mathbf{\Delta} \mathbf{H} \mathbf{5} \boldsymbol{\alpha}$ \\
\hline E. coli BL21 (DE3) & E. coli BL21 (DE3) & E. coli BL21 (DE3) \\
\hline E. coli BW25113 (DE3) & E. coli BW25113 (DE3) & E. coli BW25113 (DE3) \\
\hline E. coli BL21 Star (DE3) & E. coli BL21 Star (DE3) & E. coli BL21 Star (DE3) \\
\hline E. coli yhPA001 & E. coli yhPA001 & E. coli yhPA001 \\
\hline E. coli yhPA002 & E. coli yhPA002 & E. coli yhPA002 \\
\hline E. coli yhPA003 & E. coli yhPA003 & E. coli yhPA003 \\
\hline E. coli yhPA004 & E. coli yhPA004 & E. coli yhPA004 \\
\hline E. coli yhPA005 & E. coli yhPA005 & E. coli yhPA005 \\
\hline E. coli yhPA006 & E. coli yhPA006 & E. coli yhPA006 \\
\hline E. coli yhPA004 [pGro7] & E. coli yhPA004 [pGro7] & E. coli yhPA004 [pGro7] \\
\hline E. coli yhPA004 [pTf16] & E. coli yhPA004 [pTf16] & E. coli yhPA004 [pTf16] \\
\hline E. coli yhPA004 [pKJE7] & E. coli yhPA004 [pKJE7] & E. coli yhPA004 [pKJE7] \\
\hline E. coli $\mathbf{y h P A 0 0 4}[\mathbf{L y s P}]$ & E. coli yhPA004 [LysP] & E. coli yhPA004 [LysP] \\
\hline Plasmids & Plasmids & Plasmids \\
\hline pCDF duet-1 & pCDF duet-1 & pCDF duet-1 \\
\hline pRSF duet-1 & pRSF duet-1 & pRSF duet-1 \\
\hline pACYC duet-1 & pACYC duet-1 & pACYC duet-1 \\
\hline pET duet-1 & pET duet-1 & pET duet-1 \\
\hline pGro7 & pGro7 & pGro7 \\
\hline
\end{tabular}




\begin{tabular}{lll}
\hline Strain and plasmid & Strain and plasmid & Genotype and strain description \\
\hline pTf16 & pTf16 & pTf16 \\
pKJE7 & pKJE7 & pKJE7 \\
pCDF duet-1::pipA & pCDF duet-1::pipA & pCDF duet-1::pipA \\
pCDF duet-1::pipA::pipA & pCDF duet-1::pipA::pipA & pCDF duet-1::pipA::pipA \\
pET duet-1::pipA & pET duet-1::pipA & pET duet-1::pipA \\
pET duet-1::pipA::pipA & pET duet-1::pipA::pipA & pET duet-1::pipA::pipA \\
pET duet-1::lysP & pET duet-1::lysP & lysP gene of $E$. coli K12 inserted into pET duet-1 \\
\hline
\end{tabular}

\section{Hosted file}

Figure image.docx available at https://authorea.com/users/308932/articles/439973-enhancement-

of-pipecolic-acid-production-by-the-expression-of-multiple-lysine-cyclodeaminase-in-the-escherichiacoli-whole-cell-system 